\title{
Potential Role of Hydroxyapatite Nanocrystalline for Early Diagnostics of Ovarian Cancer
}

\author{
Ruslana Chyzhma ${ }^{1}$, Artem Piddubnyi ${ }^{1,2,3}$ (D) , Sergey Danilchenko ${ }^{4}$, Olha Kravtsova ${ }^{1,5}$ \\ and Roman Moskalenko 1,2,*(D) \\ 1 Department of Pathology, Sumy State University, 40007 Sumy, Ukraine; r.chyzhma97@gmail.com (R.C.); \\ a.piddubny@med.sumdu.edu.ua (A.P.); eriugen@i.ua (O.K.) \\ 2 Ukrainian-Swedish Research Center SUMEYA, Sumy State University, 40022 Sumy, Ukraine \\ 3 Department of Medical Biochemistry and Biophysics, Umea University, SE-90736 Umea, Sweden \\ 4 Institute of Applied Physics NAS of Ukraine, 40007 Sumy, Ukraine; danilserg50@gmail.com \\ Pathology Department, Sumy Regional Oncological Hospital, 40022 Sumy, Ukraine \\ * Correspondence: r.moskalenko@med.sumdu.edu.ua; Tel.: +380-979802731
}

check for updates

Citation: Chyzhma, R.; Piddubnyi,

A.; Danilchenko, S.; Kravtsova, O.;

Moskalenko, R. Potential Role of

Hydroxyapatite Nanocrystalline for Early Diagnostics of Ovarian Cancer. Diagnostics 2021, 11, 1741. https:// doi.org/10.3390/diagnostics11101741

Academic Editor: Luca Falzone

Received: 12 August 2021

Accepted: 16 September 2021

Published: 22 September 2021

Publisher's Note: MDPI stays neutral with regard to jurisdictional claims in published maps and institutional affiliations.

\begin{abstract}
Calcification is one of the clinical and morphological manifestations of ovarian tumors and it begins at the initial stages of carcinogenesis. Thus, this process can be used for the early diagnostics of some malignant ovarian tumors. We compared the results of ultrasound and histology and found that calcifications of a size less than $200 \mu \mathrm{m}$ are not detected by ultrasound. These calcified structures are round fragile particles of different sizes. In the EDX (Energy-dispersive X-ray spectroscopy) spectra, the main lines were from $\mathrm{Ca}$ and $\mathrm{P}$, and the ratio of these elements corresponds to hydroxyapatite. Thus, we established that hydroxyapatite is the main mineral component of ovarian psammoma bodies and could be used for early diagnostics of ovarian malignant neoplasia.
\end{abstract}

Keywords: hydroxyapatite; calcification; ovarian cancer; early diagnostics

\section{Introduction}

Ovarian cancer (OC) is one of the leading causes of death among women worldwide [1]. Ovarian neoplasia ranks fourth among malignant tumors of the reproductive system in women after breast, uterus body and cervix cancer. Despite the lower prevalence of ovarian tumors compared with breast cancer, the mortality rate of this pathology is three times higher $[1,2]$. It is related to the asymptomatic course and ineffectiveness of screening diagnosis methods.

Calcification or biomineralization is one of the clinical and morphological features of ovarian tumor manifestation [3-5]. Pathological biomineralization (PBM) is detected in about $8 \%$ of OC cases by computer tomography [6]. Calcification is more common for serous ovarian adenocarcinoma [7-9]. Histologically, the incidence of calcifications in low-grade and high-grade serous carcinomas is $100 \%$ and $50 \%$, respectively $[10,11]$. However, despite the relatively high detection rate, their prognostic and diagnostic values are not yet fully understood.

PBM in ovarian neoplasms can be divided into calcification of the stroma, capsule, tumor parenchyma, and psammoma bodies [12,13]. Pathological biomineral deposits start to develop in the earliest stages of carcinogenesis as nanocrystalline objects $[11,13]$.

The study of the microstructure and phase composition of these crystallites is required for a deeper understanding of the processes of calcification in ovarian tumors. It may be the basis for the introduction of new early diagnosis and/or treatment methods. The specific crystal-chemical features of ovarian tumor calcifications are also relevant and require more detailed study [14].

Pathological crystalline inclusions are represented by nanoparticles. In some cases, they are X-ray amorphous and this complicates the study of their structure [15]. 
Comparison of the electrogram (picture of electron diffraction) with micromorphological features of crystal particles will allow more detailed study of keynote features of specific calcification types.

The aim of our work is to establish the morphological features and phase composition of pathological minerals and determine the potential diagnostic value of $\mathrm{OC}$ nanocrystallites.

\section{Materials and Methods}

\subsection{The Ethics Committee}

The study was approved by the ethics committee of the Medical Institute of Sumy State University (Proceedings 2/7, 14 July 2021).

For this study, we used 30 cases of serous ovarian carcinoma with PBM (group 1). Thirty cases of serous ovarian carcinoma without biomineralization (group 2) were used as a control group. All tissue samples were presented with surgical material after ovaryectomy and pangisteroectomy. Patients were operated on at the Sumy Regional Clinical Oncology Hospital (Sumy, Ukraine). Informed consent was obtained from each patient prior to admission to the clinic.

\subsection{Ultrasound}

We used Toshiba Applio MX with a linear multifrequency sensor 6-12 MHz (Tokyo, Japan) for ultrasound imagining at the private clinic "Floris" (Sumy, Ukraine).

Detection of Pathological Biominerals

Calcifications with a diameter of more than $0.05 \mathrm{~cm}$ were detected during grossing. The mineral component of macroscopic calcifications was separated from soft tissues by heat treatment at $200{ }^{\circ} \mathrm{C}$ for $1 \mathrm{~h}$. This contributed to the destruction of the organic compounds of the calcification and the removal of water residues while maintaining the structure of the crystallite. Pathological biomineral formations with a diameter of less than $0.05 \mathrm{~cm}$ were detected by histology and scanning electron microscopy from histological sections of tumor tissue [16].

\subsection{Histology}

Ovarian tumor tissue was fixed in a neutral (buffered) $4 \%$ formaldehyde solution for $24 \mathrm{~h}$, dehydrated and saturated with paraffin. Paraffin blocks were sectioned with a thickness of $4 \mu \mathrm{m}$ with a Shandon Finesse 325 rotary microtome (Thermo Scientific, Waltham, MA, USA). After deparaffinization and dehydration (with xylene and ethanol), histological sections were stained with hematoxylin and eosin. All photos were captured with a digital visualization system based on a Zeiss Primo Star microscope with a Zeiss Axiocam ERc 5s digital camera and software package "Zen 2.0" (Carl Zeiss, Jena, Germany).

\subsection{Histochemistry}

To detect calcium deposition, we used von Kossa staining. Histological dehydrated sections of tumor tissue were treated with $5 \%$ aqueous solution of silver nitrate under the direct light of a $60 \mathrm{~W}$ lamp for $60 \mathrm{~min}$ followed by washing in sodium thiosulfate (5\% aqueous solution). Nuclei were counterstained with an aqueous solution of nuclear fast red for $5 \min (1: 1000)$.

\subsection{Immunohistochemistry (IHC)}

Dehydrated sections were subjected to thermal unmasking of antigen in $0.1 \mathrm{M}$ citrate buffer ( $\mathrm{pH}$ 6.0) at $95-98^{\circ} \mathrm{C}$ (Thermo Scientific, USA). We used UltraVision Quanto Detection System HRP and the DAB Quanto Detection System (Thermo Scientific, Waltham, MA, USA) for immunostaining and visualization. Sections were probed with anti-osteopontin (OPN) antibodies with dilution 1:200 (clone EPR21139-316, Abcam, Cambridge, UK). Nuclei were counterstained with Mayer's hematoxylin. We used active (tissues with previously estimated positive and negative reactions) and passive (internal) control of IHC. 


\subsection{Scanning Electron Microscopy (SEM) with EDX}

Histological sections with a thickness of $7 \mu \mathrm{m}$ were mounted on a spectrally pure graphite base. Sections were preheated at $60^{\circ} \mathrm{C}$ for $30 \mathrm{~min}$, deparaffinized and dehydrated with xylene and ethanol. We used an SEO-SEM Inspect S50-B (SEO, Sumy, Ukraine) scanning microscope with an AZtecOne energy dispersion spectrometer with an X-MaxN20 detector (Oxford Instruments plc, Abingdon, UK). EDX spectra were analyzed with standard software of the microanalysis system.

\subsection{X-ray Diffraction}

Diffractometer DRON4-07 ("Burevestnik", St. Petersburg, Russia) was used for X-ray diffraction of biominerals. Data were analyzed with the software package DIFWIN-1 (Etalon-PTC, Moscow, Russia). The phase composition identification was performed with the JCPDS database (Join Committee on Powder Diffraction Standards).

\subsection{Transmission Electron Microscopy}

A PEM-125K microscope (SELMI, Sumy, Ukraine) was used for transmission electron microscopy (TEM) with electron diffraction (ED). The powder of mineralized tissue was sonicated in distilled water with the UZDN-A sonicator (SELMI, Sumy, Ukraine). The specific power of the installation was $15-20 \mathrm{~W} / \mathrm{cm}^{2}$ at a frequency of $22 \mathrm{kHz}$. The suspension (a few drops) was applied to the vertically upward ultrasonic emitter UZDN-A and sprayed for $2-3 \mathrm{~s}$ at optimal power. The sprayed aerosol was attached to a thin carbon film $(10-20 \mathrm{~nm})$ mounted on a copper mesh of the sample holder. ED pictures and microphotographs were captured at voltage $\mathrm{U}_{\text {(acceleration) }}=90 \mathrm{kV}$.

\subsection{Statistics}

The normality of data distribution was checked by a Shapiro-Wilk test. Student's $t$-test was applied for analysis of data with a normal distribution. Mann-Whitney's U test was applied for nonparametric datasets. The results were considered statistically significant with a probability of more than $95 \%(p<0.05)$. The correlation of parameters was tested with Spearman's rank correlation coefficient. Statistical analysis was performed in Microsoft Office Excel 2016 with the addon AtteStat (version 12.0.5). All graphs were built in GraphPad Prism 7.

\section{Results}

\subsection{Ultrasound}

Ultrasound of ovaries with malignant tumors revealed solitary round hyperechogenic structures with smooth edges and clear contours, homogeneous echostructure and with no acoustic shadows. These formations ranged in size from 2 to $5 \mathrm{~mm}$ and had the avascular type of vascular pattern in the surrounding tissues (Figure 1A,B). 

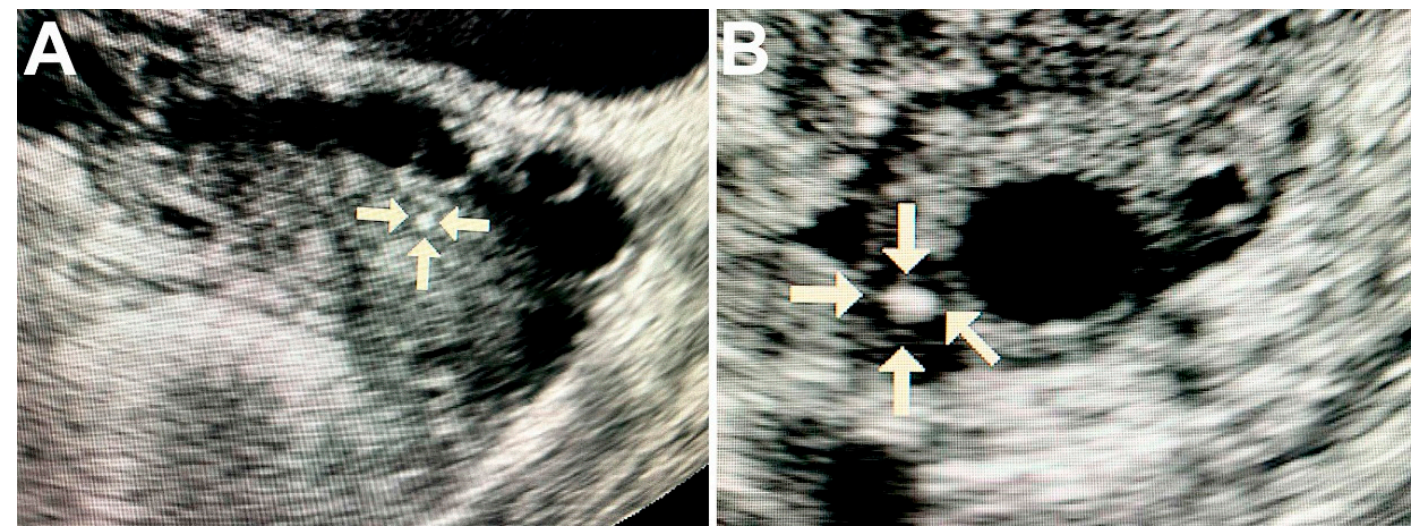

Figure 1. Ultrasound image of the ovary with pathological calcifications (marked by arrows). A-rounded biomineral structure in ovarian cancer tissue; B-the calcification is surrounded by cancerous tissue with cyst formation.

Clinical, macroscopic and ultrasound data are summarized in Table 1.

Table 1. Ovarian tumors with calcifications.

\begin{tabular}{|c|c|c|c|c|c|c|}
\hline \multirow{2}{*}{ Case } & \multirow{2}{*}{ Age of Women } & \multicolumn{3}{|c|}{ TNM } & \multirow{2}{*}{$\begin{array}{l}\text { Tumor Diameter } \\
\text { (Larger Size), mm }\end{array}$} & \multirow{2}{*}{$\begin{array}{l}\text { Diameter of Calcifications by } \\
\text { Ultrasound (Larger Size), mm }\end{array}$} \\
\hline & & $T$ & $\mathbf{N}$ & $\mathbf{M}$ & & \\
\hline 1 & 44 & $\mathrm{~T} 1$ & No & M0 & 2 & 0.5 \\
\hline 2 & 59 & $\mathrm{~T} 2$ & No & M0 & 10 & 1.0 \\
\hline 3 & 30 & $\mathrm{~T} 1$ & No & M0 & 1 & 0.25 \\
\hline 4 & 59 & $\mathrm{~T} 2$ & No & M0 & 10 & 1.0 \\
\hline 5 & 57 & $\mathrm{~T} 2$ & No & M0 & 10 & 2.0 \\
\hline 6 & 44 & $\mathrm{~T} 3$ & N1 & M0 & 15 & 2.0 \\
\hline 7 & 57 & $\mathrm{~T} 1$ & No & M0 & 5 & 1.0 \\
\hline 8 & 65 & $\mathrm{~T} 1$ & No & M0 & 3 & 0.5 \\
\hline 9 & 48 & $\mathrm{~T} 3$ & N1 & M1 & 15 & 2.0 \\
\hline 10 & 37 & $\mathrm{~T} 2$ & No & M0 & 10 & 0.8 \\
\hline 11 & 58 & $\mathrm{~T} 1$ & No & M0 & 5 & 1.0 \\
\hline 12 & 52 & $\mathrm{~T} 2$ & Nx & M0 & 10 & 1.0 \\
\hline 13 & 77 & $\mathrm{~T} 1$ & No & M0 & 2 & 0.5 \\
\hline 14 & 51 & $\mathrm{~T} 2$ & No & M0 & 10 & 1.0 \\
\hline 15 & 56 & $\mathrm{~T} 1$ & No & M0 & 2 & 0.5 \\
\hline 16 & 50 & $\mathrm{~T} 2$ & $\mathrm{Nx}$ & M0 & 10 & 1.0 \\
\hline 17 & 58 & $\mathrm{~T} 3$ & N1 & M1 & 20 & 3.0 \\
\hline 18 & 46 & $\mathrm{~T} 2$ & No & M0 & 10 & 1.0 \\
\hline 19 & 55 & $\mathrm{~T} 2$ & N0 & M0 & 10 & 1.0 \\
\hline 20 & 43 & $\mathrm{~T} 2$ & N0 & M0 & 15 & 2.0 \\
\hline 21 & 69 & $\mathrm{~T} 3$ & N1 & M1 & 20 & 4.0 \\
\hline 22 & 66 & $\mathrm{~T} 1$ & No & M0 & 5 & 1.0 \\
\hline 23 & 57 & $\mathrm{~T} 2$ & No & M0 & 10 & 2.0 \\
\hline 24 & 53 & $\mathrm{~T} 4$ & N1 & M1 & 25 & 4.0 \\
\hline 25 & 72 & $\mathrm{~T} 3$ & N1 & M0 & 15 & 3.0 \\
\hline 26 & 64 & $\mathrm{~T} 1$ & N0 & M0 & 5 & 1.0 \\
\hline
\end{tabular}


Table 1. Cont.

\begin{tabular}{|c|c|c|c|c|c|c|}
\hline \multirow{2}{*}{ Case } & \multirow{2}{*}{ Age of Women } & \multicolumn{3}{|c|}{ TNM } & \multirow{2}{*}{$\begin{array}{l}\text { Tumor Diameter } \\
\text { (Larger Size), mm }\end{array}$} & \multirow{2}{*}{$\begin{array}{l}\text { Diameter of Calcifications by } \\
\text { Ultrasound (Larger Size), mm }\end{array}$} \\
\hline & & $\mathbf{T}$ & $\mathbf{N}$ & $\mathbf{M}$ & & \\
\hline 27 & 50 & $\mathrm{~T} 2$ & No & M0 & 10 & 2.0 \\
\hline 28 & 54 & $\mathrm{~T} 1$ & No & M0 & 2 & 1.0 \\
\hline 29 & 63 & T3 & N1 & M0 & 15 & 2.0 \\
\hline 30 & 57 & $\mathrm{~T} 2$ & No & M0 & 10 & 1.0 \\
\hline
\end{tabular}

Notes: T-tumor size, $\mathrm{N}$-metastases in lymphatic nodules, $\mathrm{M}$-distant metastases. The data table of the control group is presented in the Supplementary Materials.

\subsection{Histology}

The OC tissue had micropapillary and macropapillary growths, single cells and chaotically formed small nests of cells with stroma infiltration (Figure 2A). Tumor cells were monomorphic, small, had moderate atypia of the nuclei and a defined nucleolus. Some samples of serous carcinomas were represented by solid masses with slit-like lumens, and tumor cells had large, hyperchromic, pleomorphic nuclei with chimeric configuration. Multinucleate cells with eosinophilic nucleoli were also found in tumor tissue. We found no necrotic changes in most of the serous carcinoma samples.
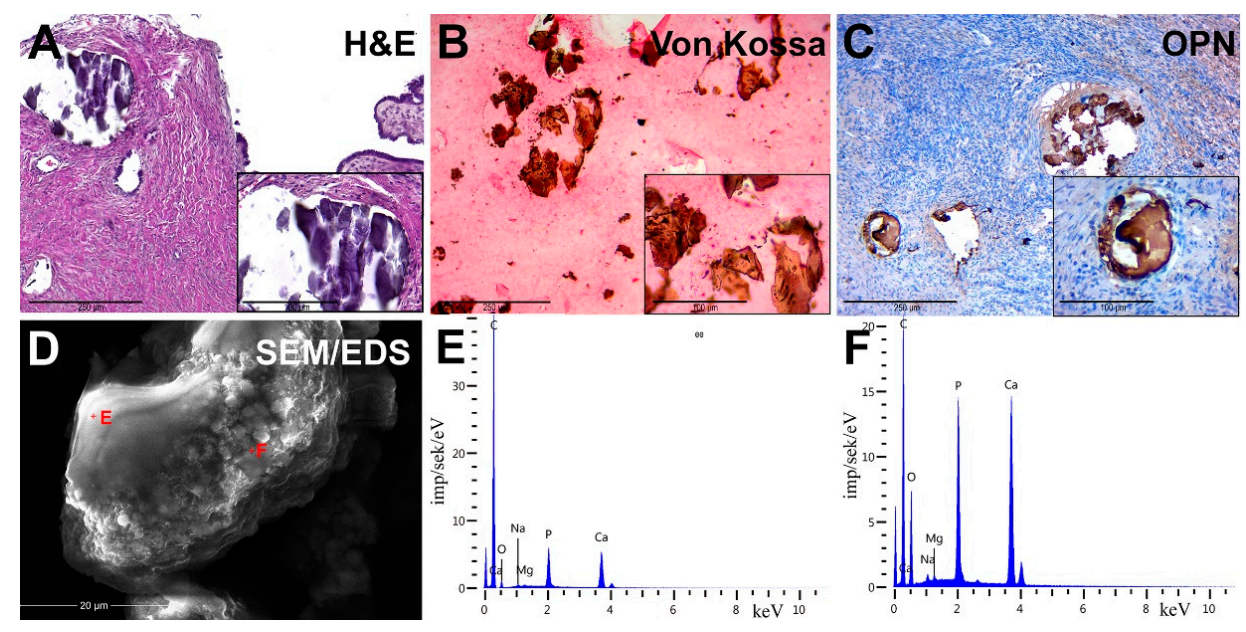

Figure 2. Pathological OC biominerals. (A) staining with hematoxylin-eosin; (B) von Kossa staining; (C) IHC detection of osteopontin (OPN); (D) Scanning Electron Microscopy (SEM) with energy-dispersive X-ray spectroscopy (EDX), analysis points are marked by red crosses; $(\mathbf{E}, \mathbf{F})$ EDX spectra of ovarian cancer calcifications.

We detected the presence of PBM as psammoma bodies (PBs) in all samples. They were represented by concentric calcified structures and their fragments had an irregular shape. PB fragments formed due to mechanical damage by a microtome knife during the sectioning. Dot-like mineral deposits with polymorphic structure were also detected. The size of these formations ranged from 10 to $300 \mu \mathrm{m}$.

\subsection{Histochemistry}

Von Kossa's staining revealed the presence of calcium phosphate. PBs and their fragments in the tumor tissue had a black and dark brown color. We noted the difference in the staining intensity between the core and outer layers of PBs (Figure 2B).

\subsection{Immunohistochemistry}

We revealed the OPN accumulation on the surface of biomineral formations by immunostaining. In general, OPN covered the surface of calcifications and was accumulated 
at the edges and between the lamellae of PBs. There was also positive cytoplasmic staining in tumor microenvironment cells, mainly in cells with mononuclear and fibroblast-like morphology (Figure 2C).

\subsection{Scanning Electron Microscopy}

SEM detected that calcifications were represented as round particles with a fragile structure and different sizes. It was confirmed by the presence of fragments of chimeric configuration. At high-power magnification, the fracture surfaces had a porous structure (Figure 2D). Nanocrystalline structures of spherical and needle shapes were found on the surface of calcifications.

In the EDX spectra, there were basic lines of $\mathrm{Ca}$ and $\mathrm{P}$, as well as lines of $\mathrm{O}, \mathrm{C}, \mathrm{Mg}, \mathrm{Na}$ and others. The ratio of the intensity of $\mathrm{Ca}$ and $\mathrm{P}$ lines corresponded to the hydroxyapatite $\mathrm{Ca}_{10}\left(\mathrm{PO}_{4}\right)_{6}(\mathrm{OH})_{2}$. However, there was a slight difference in the trace element composition, shown on spectra (Figure 2E,F).

\subsection{EDX Mapping}

According to maps of elemental distribution (Figure 3), we detected an increased concentration of calcium and phosphorus in the localization of calcified particles. Oxygen also was accumulated along with calcium and phosphorus. There was a fairly uniform distribution of carbon with no correlation with the localization of mineralized particles (calcification shielding of the carbon-containing surface of the graphite table from the electron beam).

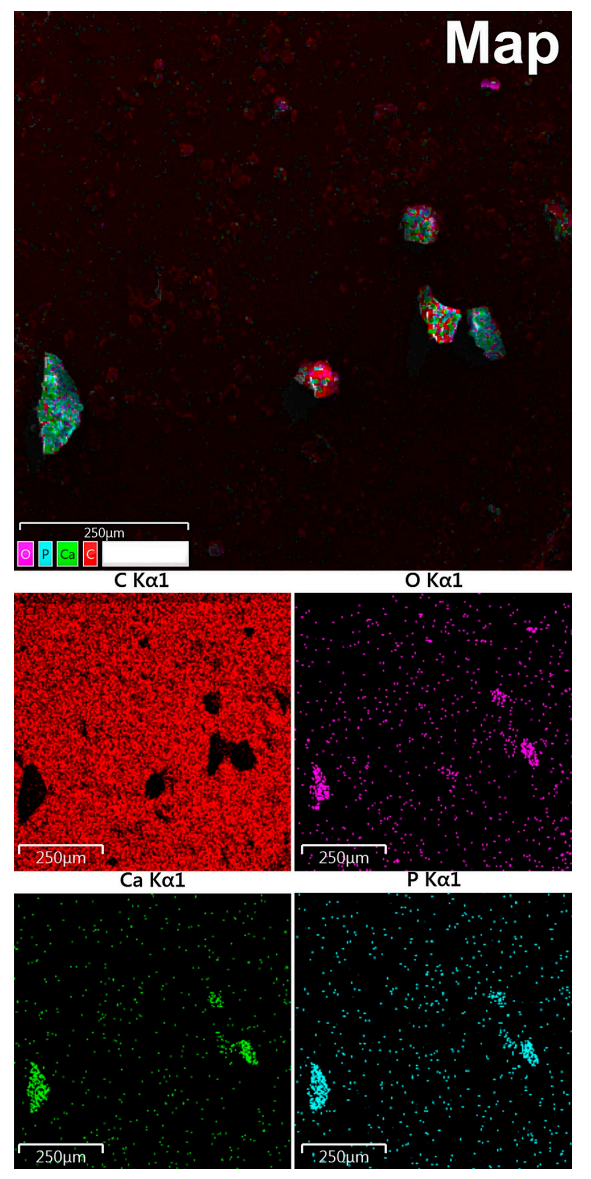

Figure 3. Study of OC calcification by EDX mapping: red indicates carbon, purple—oxygen, greencalcium, blue-phosphorus. 


\subsection{TEM}

TEM detected that apatite crystals were mostly polydisperse, but could also be monodisperse. The polycrystalline material of samples was identified by the ED pattern (Figure 4A).

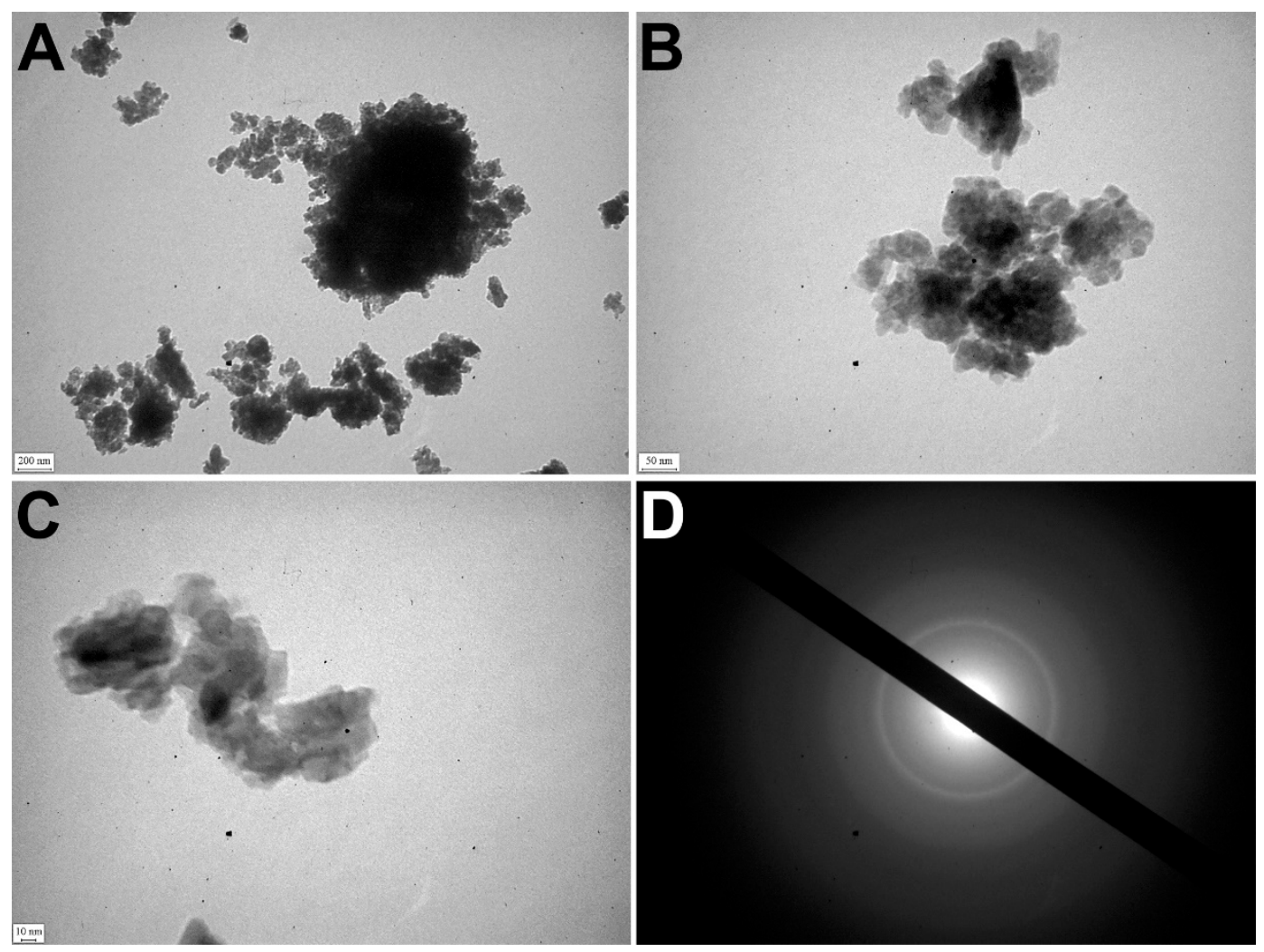

Figure 4. TEM of OC calcified samples. (A-C) TEM images of nanocrystals; (D) ED image.

The electron microscopic image showed relatively large crystals (40-50 nm) surrounded by small crystal particles (5-15 nm). It confirmed the polydisperse morphology of nanocrystals of pathological deposits (Figure 4B-D).

$X$-ray diffraction revealed that all pathological minerals were represented by calcium apatite with different levels of crystallinity (Figure 5). Similar results were previously published for biominerals of the gallbladder, prostate and thyroid gland $[16,17]$. 


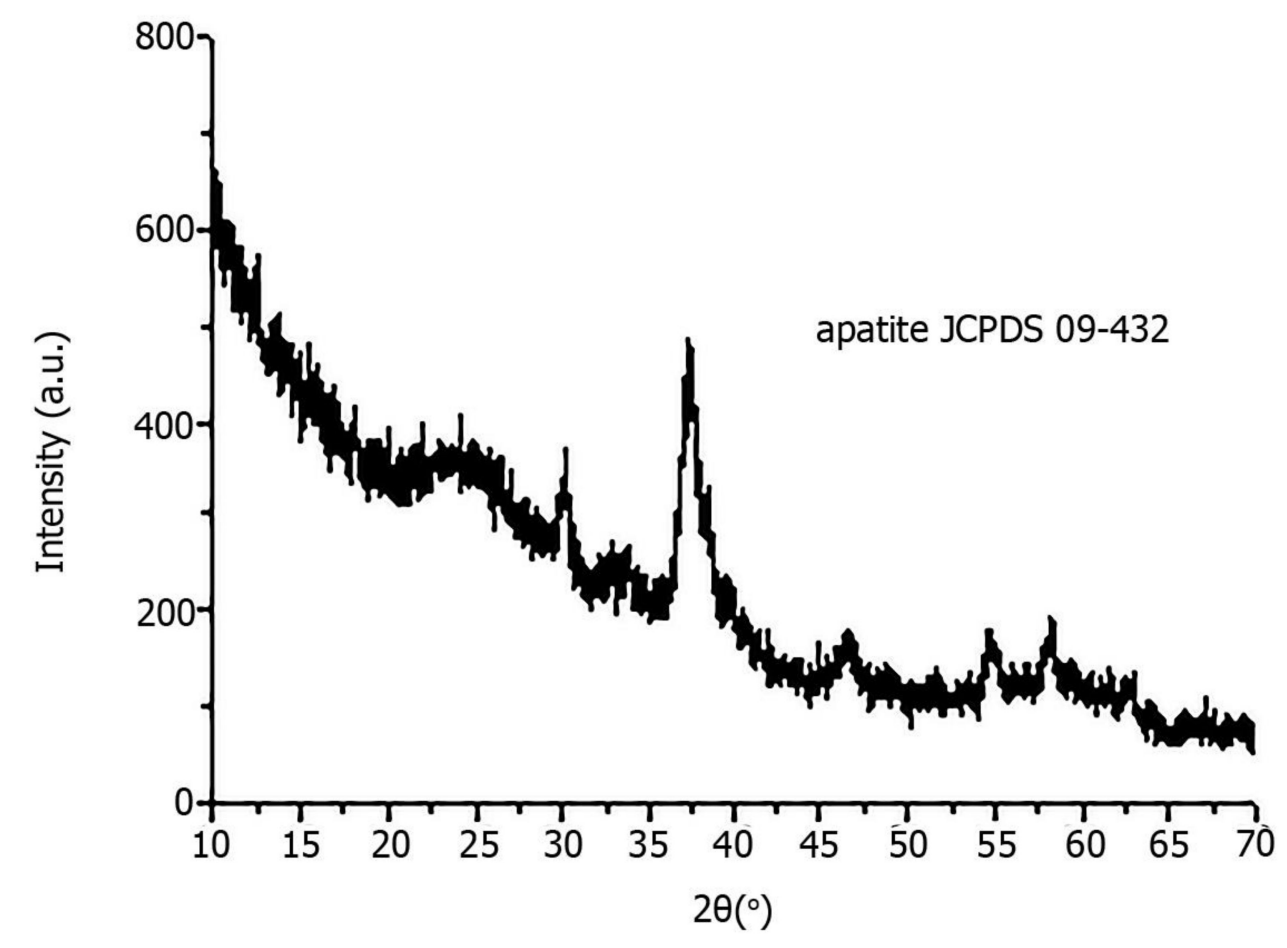

Figure 5. X-ray diffraction of pathological biomineral of ovarian tumor (sample 23).

\section{Discussion}

Calcification is one of the clinical and morphological features of ovarian tumor manifestation but it is not fully understood and needs to be studied in detail [18]. In the case of malignant ovarian tumors, the PBM begins at the earliest stages. It is caused by the partial death of malignant tumor cells. Their detritus is the basis for microcalcification development [19]. Thus, this process can be used for the early diagnostics of some malignant ovarian neoplasms.

Today, a number of routine and high-tech minimally invasive diagnostic methods are used, such as ultrasound, computed tomography (CT), magnetic resonance imaging (MRI), intravascular ultrasound (IVUS), optical coherence tomography (OCT) and positron emission tomography (PET). Technological advances make it possible to diagnose eversmaller objects. However, these methods have different resolutions (Figure 6).

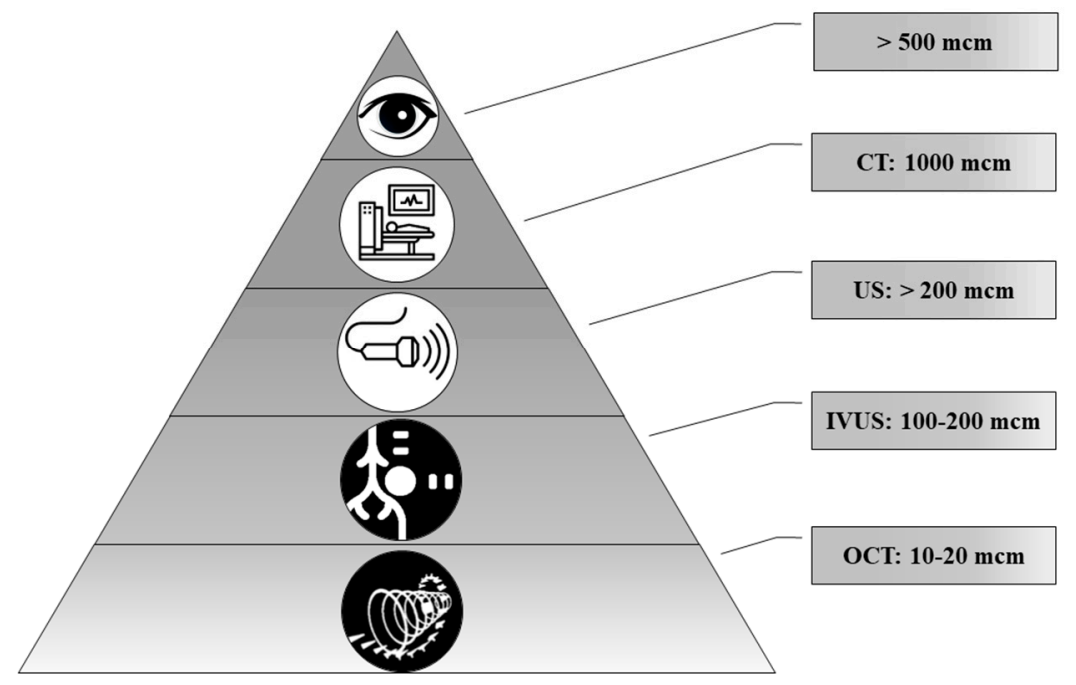

Figure 6. The representation of resolution of diagnostic methods used for biomineral detection. 
In the comparison of results of the ultrasound and histology, we noted that calcifications less than $200 \mu \mathrm{m}$ in diameter were not detected by ultrasound. At the same time, CT scans detect pathological deposits of $1000 \mu \mathrm{m}$ and bigger. IVUS visualizes calcification with a size of more than $100 \mu \mathrm{m}$. The newest high-tech and informative method is OCT. With this method, it is possible to recognize biomineral inclusions with a size of 10-20 $\mu \mathrm{m}$ and more. Shioi et al. reported that some calcifications may be X-ray amorphous [20]. This obviously depends on the composition of pathological biominerals, as well as on the maturity of the biomineral and its structure.

TEM and ED revealed the structural and morphological features of ovarian apatite crystals, which were not detected by other methods. Therefore, the development of a diagnostic method based on TEM with ED (or other high-resolution technique) in the future could improve the early diagnostics of malignant tumors with biomineralization.

We found that all biomineral deposits had calcium phosphate origin. The $\mathrm{Ca} / \mathrm{P}$ ratio corresponded to hydroxyapatite. Hydroxyapatite has a direct effect on tumor activity and behavior. It also has an inhibitory effect on tumor proliferation and induces apoptosis [21].

IHC revealed OPN accumulation on the surface of biomineral deposits. OPN has an important role in the development and formation of bone tissue and PBM [22]. It binds to the surface of calcium phosphate crystallites (e.g., hydroxyapatite) and by so doing inhibits the calcification by limiting the biomineral growth [23]. Accordingly, OPN is detected at the sites of localization of calcified particles and is an absolute and early marker of PBM and the presence of hydroxyapatite.

Therefore, the study of the structure and physical, chemical and phase composition of OC calcifications, as well as features of their visualization, is important since provides the possible practical application of this pathological phenomenon for early diagnostics of OC and other neoplasms with biomineralization.

There was no significant difference in age between two groups of patients $(p>0.05)$. We found that tumors without PBM had significantly bigger sizes $(p<0.0001)$ (Figure 7). This indicates a possible positive role (tumor suppression) of calcifications in ovarian tumors. We also found a strong correlation between tumor size and calcification $(\mathrm{r}=0.87, p<0.05)$. Thus, the detection of nanocrystalline particles will contribute to the detection of tumors at the initial stages of cancerogenesis. This confirms our hypothesis about the possible application of high-resolution techniques for early cancer diagnostics. 


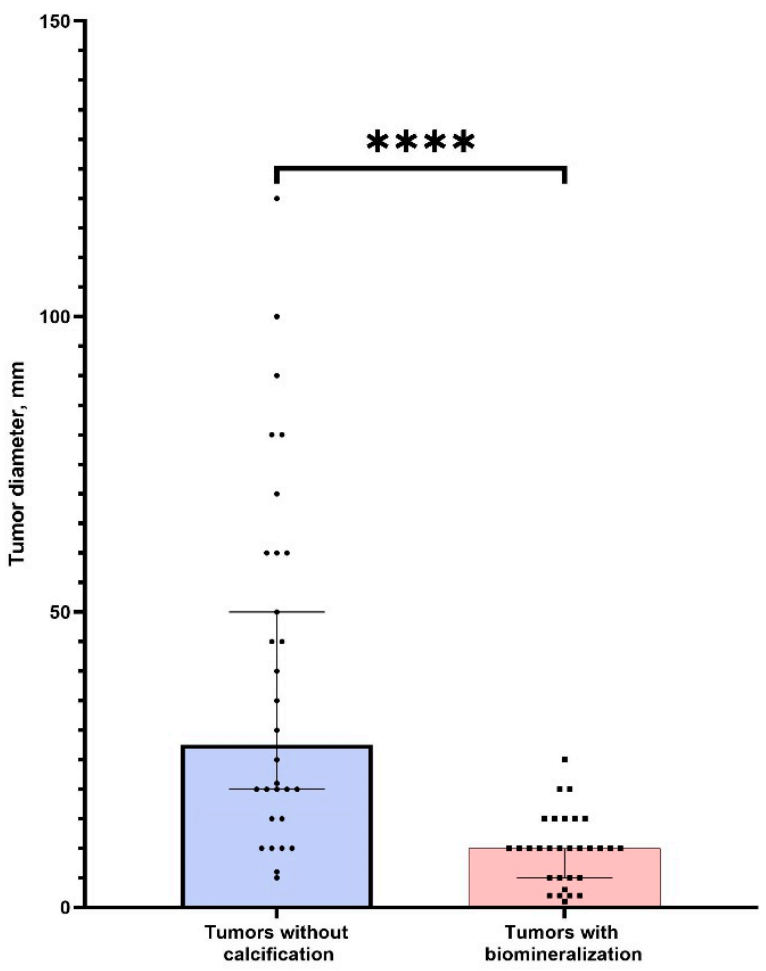

Figure 7. The comparison of tumor sizes (larger diameter) in groups of samples with the presence and absence of calcification. ${ }^{* * * *}$ corresponds $(p<0.0001)$.

\section{Conclusions}

We reported that ovarian cancer biominerals are represented by calcium apatite. No signs of other crystalline phases were detected.

The application of TEM with ED is perspective in terms of the effectiveness of highresolution methods for cancer diagnostics by detection of pathological biominerals. According to TEM, pathological crystalline nanoparticles are polydisperse and their size ranges from 5 to $50 \mathrm{~nm}$.

Thus, hydroxyapatite is the main mineral that is formed during the pathological biomineralization of ovarian malignancies. It could be used for early diagnostics of neoplasms of ovaries and other organs.

The identified relationship between tumor size and the presence or absence of calcifications is of interest for further study of the effect of hydroxyapatite compounds on tumor biology. Additionally, this fact can be used as a prognostic factor in oncology after large-scale clinical trials.

Supplementary Materials: The following are available online at https:/ /www.mdpi.com/article/10 .3390 / diagnostics11101741/s1, Table S1. Control group. Ovarian tumors without calcifications. 
Author Contributions: Conceptualization, R.M.; methodology, A.P.; investigation, R.C., S.D.; resources, O.K., R.M.; data curation, R.M.; writing-original draft preparation, R.C.; writing-review and editing, A.P., R.M.; visualization, A.P., R.M.; supervision, R.M.; project administration, R.M.; funding acquisition, R.M. All authors have read and agreed to the published version of the manuscript.

Funding: This research has been performed with the financial support of grants of the Ministry of Education and Science of Ukraine No. 0112U100471 “Condition of mineralized tissues using new composites with $\mathrm{Ag}+$ and $\mathrm{Cu} 2$ + nanoparticles".

Institutional Review Board Statement: The study was conducted according to the guidelines of the Declaration of Helsinki, and approved by Ethics Committee of the Medical Institute of Sumy State University (protocol 2/07, 14 July 2021).

Informed Consent Statement: Informed consent was obtained from all subjects involved in the study.

Data Availability Statement: Data available within the article or its supplementary materials.

Acknowledgments: We are kindly grateful to Andriy Hapchenko and Irma Repnivska for consultations and ultrasound data.

Conflicts of Interest: The authors declare no conflict of interest.

\section{References}

1. Sung, H.; Ferlay, J.; Siegel, R.L.; Laversanne, M.; Soerjomataram, I.; Jemal, A.; Bray, F. Global Cancer Statistics 2020: GLOBOCAN Estimates of Incidence and Mortality Worldwide for 36 Cancers in 185 Countries. CA Cancer J. Clin. 2021, 71, 209-249. [CrossRef] [PubMed]

2. Momenimovahed, Z.; Tiznobaik, A.; Taheri, S.; Salehiniya, H. Ovarian cancer in the world: Epidemiology and risk factors. Int. J. Women's Health 2019, 11, 287-299. [CrossRef] [PubMed]

3. Okada, S.; Ohaki, Y.; Inoue, K.; Kawamura, T.; Hayashi, T.; Kato, T.; Kumazaki, T. Calcifications in Mucinous and Serous Cystic Ovarian Tumors. J. Nippon. Med. Sch. 2005, 72, 29-33. [CrossRef] [PubMed]

4. Brown, D.L.; Laing, F.C.; Welch, W.R. Large calcifications in ovaries otherwise normal on ultrasound. Ultrasound Obstet. Gynecol. 2007, 29, 438-442. [CrossRef] [PubMed]

5. Silva, E.G.; Deavers, M.T.; Parlow, A.F.; Gershenson, D.M.; Malpica, A. Calcifications in Ovary and Endometrium and Their Neoplasms. Mod. Pathol. 2003, 16, 219-222. [CrossRef]

6. Ganeshan, D.; Bhosale, P.; Wei, W.; Ramalingam, P.; Mudasiru-Dawodu, E.; Gershenson, D.; Sun, C.; Iyer, R. Increase in posttherapy tumor calcification on CT scan is not an indicator of response to therapy in low-grade serous ovarian cancer. Abdom. Radiol. 2016, 41, 1589-1595. [CrossRef] [PubMed]

7. Koshiyama, M.; Matsumura, N.; Konishi, I. Subtypes of Ovarian Cancer and Ovarian Cancer Screening. Diagnostics 2017, 7, 12. [CrossRef] [PubMed]

8. Hatano, Y.; Hatano, K.; Tamada, M.; Morishige, K.-I.; Tomita, H.; Yanai, H.; Hara, A. A Comprehensive Review of Ovarian Serous Carcinoma. Adv. Anat. Pathol. 2019, 26, 329-339. [CrossRef]

9. Lisio, M.-A.; Fu, L.; Goyeneche, A.; Gao, Z.-H.; Telleria, C. High-Grade Serous Ovarian Cancer: Basic Sciences, Clinical and Therapeutic Standpoints. Int. J. Mol. Sci. 2019, 20, 952. [CrossRef]

10. Rosen, D.G.; Zhang, Z.; Shan, W.; Liu, J. Morphological and molecular basis of ovarian serous carcinoma. J. Biomed. Res. 2010, 24, 257-263. [CrossRef]

11. Wen, J.; Zhao, Z.; Huang, L.; Li, L.; Li, J.; Zeng, Y.; Wu, J.; Miao, Y. Switch of the ovarian cancer cell to a calcifying phenotype in the calcification of ovarian cancer. J. Cancer 2018, 9, 1006-1016. [CrossRef]

12. Fanlu, M.; Changqiu, W.; Yan, L.; Anhuai, L.; Fang, M.; Jianying, L.; Jingyun, D.; Yan, Z. Psammoma bodies in two types of human ovarian tumours: A mineralogical study. Miner. Pet. 2015, 109, 357-365. [CrossRef]

13. Das, D.K. Psammoma body: A product of dystrophic calcification or of a biologically active process that aims at limiting the growth and spread of tumor? Diagn. Cytopathol. 2009, 37, 534-541. [CrossRef] [PubMed]

14. Bonfiglio, R.; Granaglia, A.; Giocondo, R.; Scimeca, M.; Bonanno, E. Molecular Aspects and Prognostic Significance of Microcalcifications in Human Pathology: A Narrative Review. Int. J. Mol. Sci. 2020, 22, 120. [CrossRef] [PubMed]

15. Fukumoto, S. Ectopic calcification. Clin. Calcium 2014, 24, 185-189. [PubMed]

16. Moskalenko, R.; Danilchenko, S.; Piddubnyi, A.; Chorna, I.; Kolomiets, O.; Romaniuk, A. Morphological and crystal chemical characteristics of gallbladder biomineralization. Acta Fac. Med. Naissensis 2020, 327, 139-148. [CrossRef]

17. Moskalenko, R.; Romanyuk, A.; Danilchenko, S.; Stanislavov, O.; Piddubniy, A.; Zakorko, I.M.; Tkach, G. Morphogenetic as-pects of biomineralization on the background of benign prostatic hyperplasia. Georgian Med. News 2013, 214, 54-61.

18. Danilchenko, S.N.; Stanislavov, A.S.; Kuznetsov, V.; Kochenko, A.V.; Kalinichenko, T.G.; Rieznik, A.V.; Starikov, V.; Moskalenko, R.; Romaniuk, A. Structure and Morphology of Nanocrystalline Calcifications in Thyroid. J. Nano Electron. Phys. 2016, 8, 01031-1. [CrossRef] 
19. Burkill, G.J.C.; Allen, S.D.; A’Hern, R.P.; Gore, M.E.; King, D.M. Significance of tumour calcification in ovarian carcinoma. Br. J. Radiol. 2009, 82, 640-644. [CrossRef]

20. Shioi, A.; Ikari, Y. Plaque Calcification During Atherosclerosis Progression and Regression. J. Atheroscler. Thromb. 2018, 25, 294-303. [CrossRef]

21. Tang, W.; Yuan, Y.; Liu, C.; Wu, Y.; Lu, X.; Qian, J. Differential cytotoxicity and particle action of hydroxyapatite nanoparticles in human cancer cells. Nanomedicine 2014, 9, 397-412. [CrossRef] [PubMed]

22. Maki, M.; Hirota, S.; Kaneko, Y.; Morohoshi, T. Expression of osteopontin messenger RNA by macrophages in ovarian serous papillary cystadenocarcinoma: A possible association with calcification of psammoma bodies. Pathol. Int. 2000, 50, 531-535. [CrossRef] [PubMed]

23. Hunter, G.K. Role of Osteopontin in Modulation of Hydroxyapatite Formation. Calcif. Tissue Int. 2013, 93, 348-354. [CrossRef] [PubMed] 